\title{
Optimizing communication material to address vaccine hesitancy
}

\author{
Eve Dubé1,2*, Dominique Gagnon ${ }^{1}$, Maryline Vivion'
}

\begin{abstract}
Vaccine hesitancy (the reluctance to accept recommended vaccines) is a complex issue that poses risk communication challenges for public health authorities and clinicians. Studies have shown that providing too much evidence on vaccine safety and efficacy to those who are vaccine-hesitant has done little to stem the growth of hesitancy-related beliefs and fears. The objective of this paper is to describe good practices in developing communication materials to address vaccine hesitancy.

An inventory of vaccination communication materials in Canada was assessed according to the Council of Canadian Academies Expert Panel on Health Product Risk Communication Evaluation (2015). Many of the current communication products could be improved to better align with evidence-based risk communication best practices. Five best practices were identified. First, identify target audience and establish trust. Second, provide both the risks and benefits of vaccination, as most people are looking for balanced information. Third, give the facts before addressing the myths. Fourth, use visual aids. Fifth, test communication material prior to launch.
\end{abstract}

Applying these best practices to current or future communication products will help vaccine providers (including physicians, nurse practitioners, pharmacists, public health professionals) to develop communication materials that are sensitive to the complex ways that people process and value information and thus more likely to optimize vaccine uptake in their communities.
This work is licensed under a Creative Commons Attribution 4.0 International License.

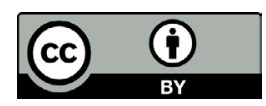

Affiliations

${ }^{1}$ Institut national de santé publique du Québec, Québec, QC

${ }^{2}$ Centre de recherche du $\mathrm{CHU}$ de Québec-Université Laval, Québec, QC

*Correspondence:

eve.dube@inspq.qc.ca

Suggested citation: Dubé E, Gagnon D, Vivion M. Optimizing communication material to address vaccine hesitancy. Can Commun Dis Rep 2020;46(2/3):48-52. http://doi.org/10.14745/ccdr.v46i23a05

Keywords: vaccine hesitancy, communication, vaccine uptake, information products, risk communication, vaccine acceptance, vaccine misinformation

\section{Introduction}

Studies have shown that providing evidence of vaccine safety and efficacy to those who are vaccine-hesitant has done little to stem the growth of hesitancy-related beliefs and fears. Previous research has shown that messaging that too strongly educates and advocates vaccination can be counterproductive for those who are already hesitant (1). Providing too much information can even generate hesitancy (2). To address this paradoxical effect of some communication material, research has been done on what communication techniques and strategies are most effective. Research evidence of what works (or not) in health risk communication has been compiled by Fischhoff and colleagues (3) and endorsed as good practices by the Council of Canadian Academies Expert Panel on Health Product Risk Communication Evaluation (4). To explore how Canadian communication material reflects these best practices, we assessed an inventory of Canadian vaccination communication materials (websites, factsheets, posters, videos, etc.) using Fischhoff's good practices (3).

Although the communication of information is one of the primary tools at the disposal of vaccine providers, information alone is unlikely to dramatically change vaccine acceptance. Given the amount of financial and human resources invested in developing and diffusing communication materials about vaccination, it is critical to optimize these tools to ensure that they work as intended. The objective of this paper is to describe good practices in developing communication materials to address vaccine hesitancy. This is the second of a series of articles, produced by the Canadian Vaccination Evidence Resource and Exchange Centre (CANVax), which includes both the identification of existing resources and the creation of new resources by this group of multidisciplinary professionals $(5,6)$. 


\section{General observations}

Our analysis showed that existing communication materials in Canada could be improved to better align with established best practices in risk communication. We found that most communication material focused on risks of vaccine-preventable diseases, the risks of adverse events and "debunking common myths". The approaches used to debunk myths generally focused on the myth itself rather than the correct information. We found the information about risk was mainly qualitative (e.g. "The risk of adverse events after immunization is small" and "The diseases we can prevent with vaccines can lead to pneumonia, deafness, brain damage, heart problems, blindness and paralysis in children who are not protected"). Few of the materials used probabilities to quantify risks. When probabilities appeared, they were unidirectional (e.g. presenting only risk of diseases or number of cases in an outbreak) rather than bidirectional (e.g. presenting risk of diseases and risk of adverse events after immunization). Only a minority of the materials used graphics or videos.

We then did a limited scan of international materials and found that some communication tools that have been developed do meet best practices and could be adapted for Canadian parents (e.g. http://talkingaboutimmunisation.org.au/).

\section{Best practices}

Addressing vaccine hesitancy requires tailored strategies that are tested, evidence-informed and take into account that vaccine hesitancy is complex and context specific, varying across time, place and vaccine type (7).

\section{Identify target audience and establish trust}

"Understanding the perspectives of the people for whom immunization services are intended, and their engagement with the issue", wrote Goldstein and colleagues, "is as important as the information that experts want to communicate" (8). The amount, content and type of information that is needed to move a vaccine-hesitant individual toward vaccine acceptance differs greatly from the basic information needed by a person who is already favourable to vaccination and intends to vaccinate. Research has shown that vaccine-hesitant individuals are "active information-seekers" that are looking for "balanced" information presenting both pros and cons of vaccination in order to make an informed decision about vaccines $(9,10)$. Their information needs are usually not fulfilled with typical information from public health authorities, as this information generally does not usually provide references to scientific studies and is often perceived as focusing on the benefits of vaccines and not discussing the potential risks of vaccines (11). Addressing those who are strongly anti-vaccines merit specific strategies. This is not the subject of the current paper but will be addressed in a future CANVax Brief.
A key factor influencing vaccination decision-making is trust in the effectiveness and safety of vaccines, in the system that delivers them, including the reliability and competence of the health services and health professionals, and in the motivations of the policy-makers who decide which vaccines are needed when and where (11). Many studies have shown that vaccine hesitancy was not due to being uninformed or misinformed, but reflected a general distrust of doctors, government sources and/or pharmaceutical companies (12-14). In this context, the perceived credibility of the institutions delivering the vaccination information often matters more than the information itself (15), highlighting the importance of transparency and honesty (16). Presenting both the potential benefits and potential harms of vaccines is also key. Studies in other countries have shown this to be a promising approach for increasing vaccine acceptance (17-19).

Research has shown that individuals, when faced with information that contradicts their values, can feel threatened and react defensively. This creates resistance, resulting in a strengthening of their initial beliefs and reducing the likelihood of engaging in the desired behavior (i.e. vaccination acceptance) (20). However, messages can be framed in ways that addresses patients' values and promotes trust (21). For example, when human papilloma virus vaccination was framed as a cancer-prevention vaccination, less resistance was generated than when it was framed as a means to prevent a sexually transmitted infection (22).

\section{Provide both the risks and benefits of vaccination}

Providing information about the risk and benefits of vaccination is not as simple as it might seem (3). When developing communication material, healthcare workers must be sensitive to the complex ways by which people process and value information. Do not assume that "numbers will speak for themselves". How the message is developed is as important as the content (23): while the content of the tools should be based on available scientific evidence, the development should be based on risk communication (24).

Best practices arising from this literature review include providing data on risks and benefits of vaccination and providing critical qualitative information:

- Providing numeric likelihood of risks and benefits of vaccination

Tools should clearly define both the risks and potential consequences of not being vaccinated (risks of vaccinepreventable diseases) and the risks of adverse events after vaccination. This should be done using not just words but also numbers. Keep denominators constant (e.g. one in 10,000; 25 in $10,000)$ and use whole numbers rather than fraction or decimals $(25,26)$. 
- Providing critical qualitative information

Material should not only present quantitative numeric information on vaccination risks and benefits, but should also provide qualitative information to present the evidence supporting these estimates. Focus on the critical information and why it is critical that people understand this information in order to make their vaccination decision. For example, people might not realize that their individual vaccination decision has an impact on herd immunity, or parents may not understand that postponing vaccination is an option.

\section{Give facts; then address myths}

One of the main objectives of most communication material on vaccination is to "correct" misconceptions about vaccination. But communication material needs to be carefully designed, as attempts to debunk a myth could actually reinforce it (20). When developing communication material, put the emphasis on the facts, not the myths. The common technique of headlining the vaccination myth in big, bold letters is not the best strategy, as people will remember the myth, not the fact. Instead, communicate the core fact in the headline, and then followup with an alternative explanation. When a myth is debunked, a gap in the person's mind is created. To be effective, the communication material must then fill that gap (Figure 1).

\section{Use visual aids}

Visual supports like infographics or video can enhance a person's understanding of complex risk information. Studies have shown that visual aids may help people to understand health risks, especially for those with low numeracy skills $(27,28)$. Visual aids include videos, pictures, icons array (i.e. a picture using one shape that is repeated a specific number of times, usually 10,100 or 1,000 , with some of the shapes altered, usually in a different color, to represent a proportion) or infographics (i.e. a combination of images and text to quickly summarize a large amount of information). Graphs can make numeric information easier to understand and pictographs are the best strategy for communicating both gist (meaning) and verbatim (exact details) knowledge (Figure 2).

\section{Figure 2: A short introduction on vaccine safety by Immunize Canada}

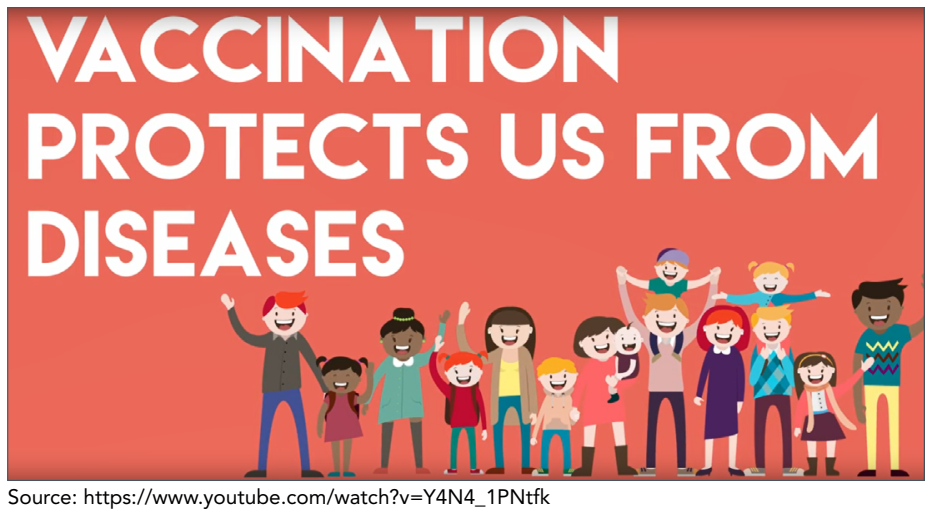

Figure 1: Addressing vaccination myths

\section{ADDRESSING VACCINATION MYTHS}

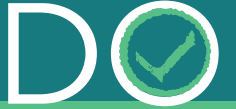

() Emphasize the fact

() Give alternative explanation to fill the gap Q Provide references $\otimes$ Emphasize the myth

$\otimes$ Give no alternative explanation for the potential causes of autism

$\otimes$ Use complex language

\section{DO VACCINES} CAUSE AUTISM?

Many large studies have found that vaccines do not cause autism.

HOW DO WE KNOW? Many good studies have compared the health of large numbers of vaccinated and unvaccinated children over many years and found that vaccinated and unvaccinated children were as likely to develop autism. (References to scientific studies).

THEN WHAT CAUSES AUTISM?

It is not known exactly why some children develop autism. Current research suggest that autism has many causes. (References to scientific studies).
Medical researchers and scientists around the world have NOT found a link between vaccines and autism.

The study that had initially reported a link between the measles-mumps-rubella (MMR) vaccine and autism was RETRACTED in 2011.

EVIDENCE-BASED REVIEWS have rejected any casual associations between the MMR vaccine and autism spectrum disorders in children. 


\section{Test communication prior to launching}

It is important to test a communication material prior to launching to make sure it is working as intended for the target audience. The results might be surprising: a study showed that information given in frequency formats (e.g. one out of 10 infants will have a fever after a vaccination) were perceived as more risky than the same information conveyed in probabilistic terms (e.g. $10 \%$ of infants will have a fever after a vaccination) (27). Studies have also shown that as many as one out of two adults do not have the necessary skills to interpret probabilities and other mathematical concepts $(27,28)$.

- Use communication material that is clear and easy to understand

Use simple language, short sentences and subheadings. Avoid dramatic language and derogatory comments that alienate people. It is important that numbers used are easy to understand (28).

- Avoid the back-fire effect

For those who are strongly fixed in their views, being confronted with counter-arguments can cause their views to be strengthened (29). Testing communication material is important, as even carefully crafted efforts to influence individuals holding factually incorrect beliefs can, in fact, reinforce these beliefs (29).

\section{Conclusion}

Risk messaging cannot be "one-size-fits-all". Most people are seeking balanced information on vaccines when deciding whether to take them or not. People need to verify with their health care provider that there is misinformation on vaccines. People with strong antivaccination views may not change their minds, regardless of what the message is or how it is communicated, so short messaging may be all that is indicated. To address the spectrum of beliefs that contribute to vaccine hesitancy, communication materials need to be tailored and targeted to these different knowledge systems, and the unique information needs and preferences of particular communities $(8,23)$. Updates on this issue will be published on the CANVax website (5).

\section{Authors' statement}

ED - Conceptualization, supervision, writing-original draft

DG - Writing — review and editing

MV - Data curation, formal analysis, writing - review and editing

\section{Conflict of interest}

Dr. Dubé reports grants from the Public Health Agency of Canada, the Quebec ministry of Health and Social services, le Fonds de recherche en Santé du Québec, the Canadian Institutes of Health Research, the Canadian Immunization Research Network, and the Social Sciences and Humanities Research Council of Canada. Dr. Vivion reports grants from Canadian Public Health Association and from Canadian Immunization Research Network during the conduct of the study.

\section{Funding}

The analysis of communication material was supported by the Canadian Immunization Research Network under Grant 385094. The development of the CANVax Briefs are supported by the Immunization Partnerships Funds of the Public Health Agency of Canada.

\section{References}

1. Nyhan B, Reifler J. Does correcting myths about the flu vaccine work? An experimental evaluation of the effects of corrective information. Vaccine 2015 Jan;33(3):459-64. DOI PubMed

2. Scherer LD, Shaffer VA, Patel N, Zikmund-Fisher BJ. Can the vaccine adverse event reporting system be used to increase vaccine acceptance and trust? Vaccine 2016 May;34(21):2424-9. DOI PubMed

3. Fischhoff B, Brewer N, Downs J, editors. Communicating Risks and Benefits: An Evidence-based User's Guide. Silver Springs (MD): US Department of Health and Human Services; 2011. https://www.fda.gov/media/81597/download

4. Council of Canadian Academies. The Expert Panel on the Effectiveness of Health Product Risk Communication. Health Product Risk Communication: Is the Message Getting Through? Ottawa (ON): CCA, 2015. https://cca-reports. $\mathrm{ca} /$ reports/health-product-risk-communication-is-the-mess age-getting-through/

5. CANVax. The Canadian Vaccination Evidence Resource and Exchange Centre. Ottawa (ON). https://www.canvax.ca/

6. MacDonald NE, Dubé $E$. A new resource to summarize evidence on immunization from the Canadian Vaccination Evidence Resource and Exchange Centre (CANVax). Can Commun Dis Rep 2020;46(1):16-9. DOI

7. MacDonald NE; SAGE Working Group on Vaccine Hesitancy. Vaccine hesitancy: Definition, scope and determinants. Vaccine 2015 Aug;33(34):4161-4. DOI PubMed 
8. Goldstein S, MacDonald NE, Guirguis S; SAGE Working Group on Vaccine Hesitancy. Health communication and vaccine hesitancy. Vaccine 2015 Aug;33(34):4212-4. DOI PubMed

9. Wheeler M, Buttenheim AM. Parental vaccine concerns, information source, and choice of alternative immunization schedules. Hum Vaccin Immunother 2013 Aug;9(8):1782-9. DOI PubMed

10. Sobo EJ, Huhn A, Sannwald A, Thurman L. Information curation among vaccine cautious parents: Web 2.0, Pinterest thinking, and pediatric vaccination choice. Med Anthropol 2016 Nov-Dec;35(6):529-46. DOI PubMed

11. Dubé E, Vivion M, Sauvageau C, Gagneur A, Gagnon R, Guay M. "Nature Does Things Well, Why Should We Interfere?": Vaccine Hesitancy Among Mothers (Canada). Qual Health Res 2016 Feb;26(3):411-25. DOI PubMed

12. Attwell K, Ward PR, Meyer SB, Rokkas PJ, Leask J. "Do-ityourself": vaccine rejection and complementary and alternative medicine (CAM). Soc Sci Med 2018 Jan; 196:10614. DOI PubMed

13. Ward PR, Attwell K, Meyer SB, Rokkas PJ, Leask J. Risk, responsibility and negative responses: a qualitative study of parental trust in childhood vaccinations. J Risk Res 2017;21(9):1117-30. DOI

14. Attwell K, Leask J, Meyer SB, Rokkas P, Ward P. Vaccine Rejecting Parents' Engagement With Expert Systems That Inform Vaccination Programs. J Bioeth Inq 2017 Mar;14(1):65-76. DOI PubMed

15. Yaqub O, Castle-Clarke S, Sevdalis N, Chataway J. Attitudes to vaccination: a critical review. Soc Sci Med 2014 Jul;112:111. DOl PubMed

16. MacDonald NE, Smith J, Appleton M. Risk perception, risk management and safety assessment: what can governments do to increase public confidence in their vaccine system? Biologicals 2012 Sep;40(5):384-8. DOI PubMed

17. Haase N, Schmid P, Betsch C. Impact of disease risk on the narrative bias in vaccination risk perceptions. Psychol Health 2019 Sep;(epub ahead of print):1-20. DOl PubMed

18. Nan X, Madden K. HPV Vaccine Information in the Blogosphere: How Positive and Negative Blogs Influence Vaccine-Related Risk Perceptions, Attitudes, and Behavioral Intentions. Health Commun. Nov;27(8):829-36. DOI
19. Daley MF, Narwaney KJ, Shoup JA, Wagner NM, Glanz JM. Addressing Parents' Vaccine Concerns: A Randomized Trial of a Social Media Intervention. Am J Prev Med 2018 Jul;55(1):44-54. DOI PubMed

20. Cook J, Lewandowsky S. The Debunking Handbook. St. Lucia, Australia: University of Queensland, 2011. https:// skepticalscience.com/docs/Debunking_Handbook.pdf

21. Kahan DM. Social science. A risky science communication environment for vaccines. Science 2013 Oct;342(6154):53-4. DOl PubMed

22. Vorpahl MM, Yang JZ. Who Is to Blame? Framing HPV to Influence Vaccination Intentions among College Students. Health Commun 2018 May;33(5):620-7. DOI PubMed

23. Parrish-Sprowl J. Vaccine hesitancy communication: what counts as evidence. Vaccine 2018 Oct;36(44):6529-30. DOI PubMed

24. Thomson A, Vallée-Tourangeau G, Suggs LS. Strategies to increase vaccine acceptance and uptake: from behavioral insights to context-specific, culturally-appropriate, evidence-based communications and interventions. Vaccine 2018 Oct;36(44):6457-8. DOI PubMed

25. Downs J, Fischhoff B. Qualitative Information. In: Fischhoff B, Brewer N, Downs J, editors. Communicating Risks and Benefits: An Evidence-based User's Guide Silver Springs: US Department of Health and Human Services; 2011. (Chapter 8). https://www.fda.gov/about-fda/reports/ communicating-risks-and-benefits-evidence-based-usersguide

26. Fagerlin A, Peters E. Quantitative Information. In: Fischhoff B, Brewer N, Downs J, editors. Communicating Risks and Benefits: An Evidence-based User's Guide. Silver Springs: US Department of Health and Human Services; 2011. (Chapter 7). https://www.fda.gov/ about-fda/reports/communicating-risks-and-benefit s-evidence-based-users-guide

27. Peters E. Numeracy and the perception and communication of risk. Ann N Y Acad Sci 2008 Apr;1128:1-7. DOI PubMed

28. Peters E. Beyond comprehension: the role of numeracy in judgments and decisions. Curr Dir Psychol Sci 2012;21(1):315. DOI

29. Nyhan B, Reifler J, Richey S, Freed GL. Effective messages in vaccine promotion: a randomized trial. Pediatrics 2014 Apr;133(4):e835-42. DOl PubMed 